\title{
Wikipedia as a Disruptive Translation Environment: An Analysis of the Istanbul/Ístanbul Controversy
}

\author{
Henry Jones
}

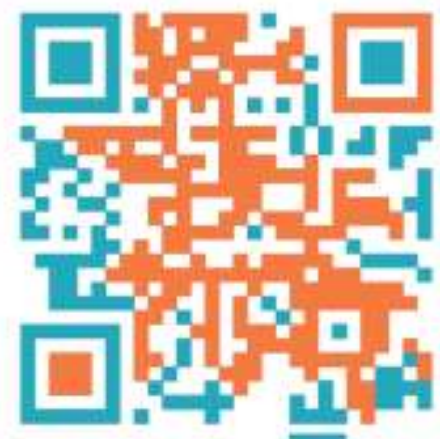

\author{
Henry Jones
}

revista.trádumàticả

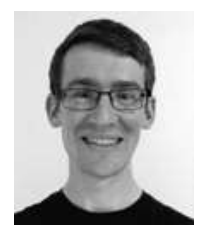

Henry Jones

Centre for Translation and Intercultural Studies

University of Manchester, UK henry.jones@manchester.ac.uk; ORCID: $\quad$ 0000-0003-4544$\underline{3086}$
Abstract

This article presents a case-study focused on the collaborative construction of the English-language Wikipedia article about 'Istanbul'. It tracks the evolution of a heated debate revolving around the city's name and highlights the extent to which translation practices in this online environment are shaped by the website's disruptive digital geography.

Keywords: Wikipedia; volunteer translation; digital disruption; online communities.

\section{Resum}

Aquest article presenta un estudi de cas centrat en la redacció collaborativa de l'article anglès de la Viquipèdia sobre Istanbul. Segueix l'evolució del debat acalorat que hi va haver sobre el nom de la ciutat $i$ subratlla fins a quin punt la geografia digital disruptiva d'aquest lloc web modela les pràctiques de traducció en aquest entorn en línia.

Paraules clau: Viquipèdia; traducció voluntària; disrupció digital; comunitats en línia.

\section{Resumen}

Este artículo presenta un estudio de caso centrado en la elaboración colaborativa del artículo de Wikipedia en inglés sobre Estambul. Sigue la evolución del debate encendido sobre el nombre de la ciudad y resalta hasta qué punto la geografía digital disruptiva de este sitio web modela las prácticas de la traducción en este entorno en línea.

Palabras clave: Wikipedia; traducción voluntaria; disrupción digital; comunidades en línea. 


\section{Introduction}

First introduced in 1995, the term 'wiki' refers to a particular class of network software designed to facilitate quick and easy online collaboration between any number of geographically dispersed individuals (Leuf and Cunningham, 2001). As such, wikis are widely hailed as one of the most successful examples of commons-based peerproduction technologies and as a quintessential feature of the new 'participatory' internet (Benkler, 2002; Shirky, 2008; Jones, forthcoming). While for much of the 1990s the web was for most consumers a "browsing-only medium", wikis' development has been instrumental to the rise of a more interactive model for information sharing (Reagle, 2010: 39). With the editing functionality of their webpages placed directly on the server, wiki users are no longer limited to the passive consumption of static, viewonly text and images; instead, they are able to manipulate these new software tools to communicate and collaborate via the internet with unprecedented ease, speed and freedom (Leuf and Cunningham, 2001: 8). Wikis have thus allowed new forms of community, creativity and cultural expression to emerge over the past two decades, often with radically disruptive consequences for the dominant practices and structures of the media, education and politics (Jones, forthcoming).

An especially high-profile example of such digital disruption is Wikipedia, an online phenomenon born out of the application of wiki software to the processes of constructing a multilingual encyclopedia. Since at least the beginning of the nineteenth century, reference works of this kind have conventionally solicited only the contributions of experts and expert forms of knowledge (Hartelius, 2010: 510). In marked contrast, Wikipedia allows - and actively encourages - any one of its readers to add to, improve, remove or otherwise alter its content. As the site's tagline advertises, it is "the free encyclopedia that anyone can edit" (Wikipedia, "Main page"). In this way, the power to assert information as fact has been transferred from a small elite group of scientists, historians and other academic writers, to everyone and anyone with the time, technical wherewithal and inclination to participate. As a result, the platform is currently home to at least 220,000 regular volunteer contributors, selfselected not on the basis of their professional expertise, academic qualifications or institutional affiliation, but instead their shared interest in and broad commitment to the goal of creating a free online knowledge resource (Wikimedia, "Wikipedia editor activity statistics"). Indeed, Wikipedia may have started as the pet project of a small band of programmers mostly associated with the Free and Open Source Software (FOSS) movement (Reagle, 2010: 77) but, as Sue Gardner (2013) has written, it now constitutes an increasingly diverse global community from "pretty much every ethnicity, nationality, socioeconomic background, political ideology, religion, sexual orientation and gender."

Despite the multinational diversity of the project, however, the disruptive effects of wikis as they relate to issues of language and translation in Wikipedia remain underexplored (Jones, 2018; Shuttleworth, 2017). Julie McDonough Dolmaya (2012; 2015) has investigated the motivations of the multilingual users who translate content between the different language editions of Wikipedia and assessed the quality of translations produced via this 'crowdsourcing' model. Her most recent contribution (McDonough 
Dolmaya, 2017) additionally provides insight into the linguistic policies of Wikipedia and the Wikimedia Foundation (the umbrella organisation that hosts the encyclopedia and a number of other wiki-based knowledge projects). Nevertheless, little attention has so far been paid to the impact that the precise characteristics of wiki technologies themselves might have on the various forms of translation that take place within the platform, especially with regard to specific translation problems. Consequently, this article presents a case-study focused on the English-language Wikipedia article currently entitled 'Istanbul' with the aim of elucidating the extent to which this article's construction has been shaped by the destabilising digital geography of this new translation environment.

\section{Wikipedia: Istanbul}

According to the entry's 'Revision history', the English-language Wikipedia article about the city of Istanbul, Turkey, was first created at 16:55 on 19 July 2001 (Xtools, "Istanbul: Page History"). As of 31 January 2018, it has since received 11,634 'edits' by 3,527 individual contributors. The graph in Figure 1 shows, however, that the most intense period of editing activity and article growth took place in 2006 and 2007, during which time the text quintupled in size thanks to well over 3,000 contributions. The page then remained highly active for five further years, receiving an average of three edits a day between 1 January 2008 and 31 December 2012 (total: 5,695 edits).

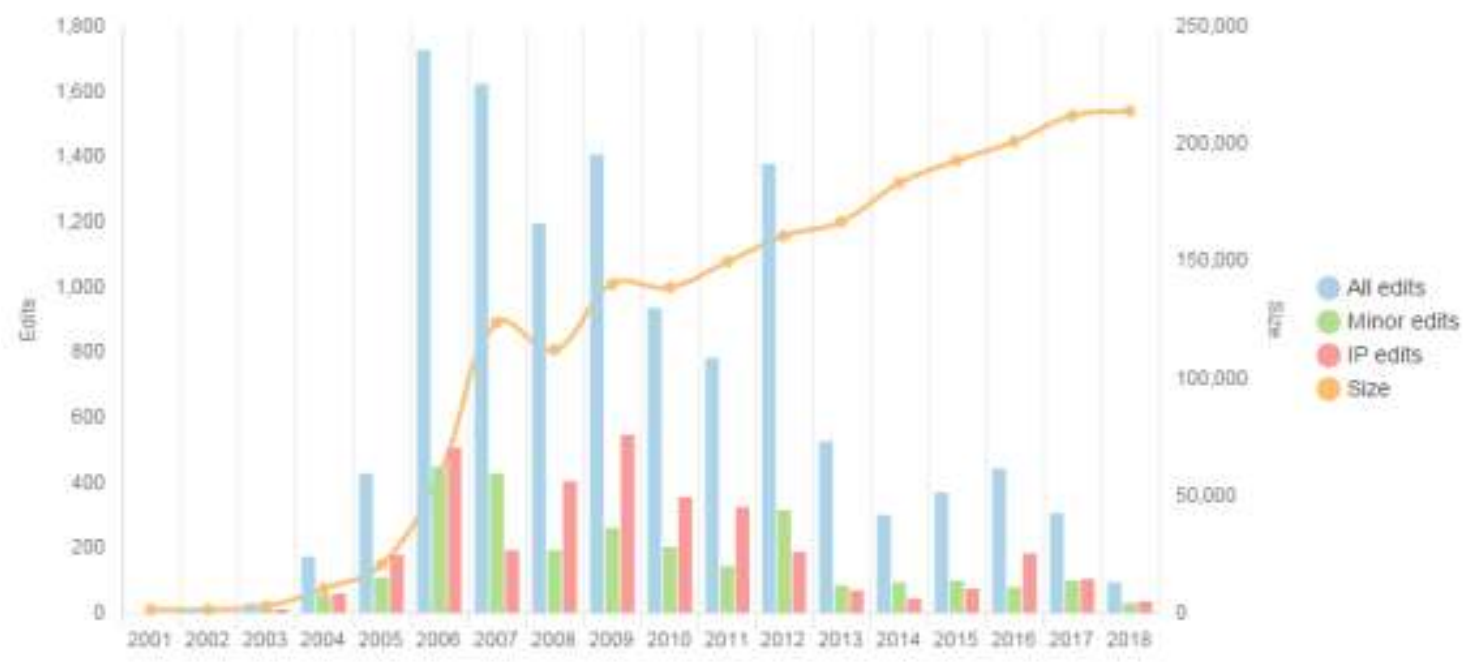

Figure 1: Graph visualising the 'Revision History' of the English-language Wikipedia article about Istanbul, Turkey (Source: Xtools, "Istanbul: Page History").

Investigation of the so-called 'Talk Page' discussion forum connected to this Wikipedia article and archived automatically by the software provides some indication as to the main challenges faced by its community of volunteer authors during this important stage in the text's development (see Wikipedia, "Talk: Istanbul", Archives 1 to 7). Indeed, even a quick perusal of the titles of the discussion threads recorded here reveals that - as is the case in many Wikipedia entries (see Hautasaari and Ishida 
2011: 128) - the issue of the city's name has proved particularly thorny: examples of these subject titles include "Istanbul or Constantinople?" "Istanbul naming", "Information from anonymous contributor on 'Islamabol' name" and "Name in which languages?". This is particularly interesting for our purposes here because many of the Wikipedians involved in the debate conceptualise the difficulty as being primarily "about Translation [sic]" (Xsara, 11:39, 20 October 2006, Archive 2). To be precise, the argument revolves around whether or not the city's local name(s) should be translated, which name(s) can be considered legitimate 'source texts' for such a translation, and how to present any target-language (i.e. English) rendering in the encyclopedia text.

Of these three friction points, the first appears to be the least controversial: the policy of non-translation whereby the city's locally official endonym, 'Istanbul' (note the diacritic), might be transferred directly across into the English-language entry elicits the support of only a small number of Wikipedians during this period. Contributors AlexanderFreud and Infestor make strong arguments in favour of this strategy, noting that in the English Wikipedia "all the other Turkish cities (e.g. Iğdır, Gümüşhane, Çanakkale) have their name written in Turkish alphabet but İstanbul. How is this logical again?" (Infestor, 13:19, 11 September 2012, Archive 7). Yet, as tariqabjotu explains, for "[a]ll of the articles Infestor mentions $[\cdots]$ there really are no English equivalents. For that reason, all of those cities have just one name in their respective infoboxes the name as it's written in Turkish. That's not the case here" (01:21, 18 September 2012. Archive 7). Another comment posted to the forum a few years earlier provides further insight into why so few contributors appear to be in favour of non-translation: "[a]ll governments in the world", DeliDumrul (14:50, 23 June 2006, Archive 2) writes, "use Istanbul when corresponding in English, so as all the English media." In other words, the fact that 'Istanbul' is most commonly translated into 'Istanbul' in institutionally produced English discourse, rather than being left in its source-language form, is seen as a primary justification for Wikipedia to adopt this strategy too. Thus, for much of the article's history, the English-language toponym 'Istanbul' is used both as the article title and throughout the body of the text (see Figure 2).

\section{Istanbul}

From Wikipedia, the free encyclopedia

For other uses, see Istanbul (disambiguation).

Istanbul (/. Istæn'bul/ or / Istæn'bu:I/ or /I'stænbul/;[8][9] Turkish: İstanbul [is 'tanbuł] ( listen)),

Figure 2: A first translation solution

More controversial is the question of what should be displayed as the source text for this translation. In the screenshot presented in Figure 2, for example, we see the Turkish name alone is placed in parentheses; its pronunciation is also offered via an IPA transcription, alongside a hyperlink to an audio recording. This source text is included, according to DeliDumrul (14:50, 23 June 2006, Archive 2), because this 
"would be what you see when you go to the city." In a sense, therefore, it is provided to inform the target-language reader of the fact of translation, i.e., of the difference between the English and Turkish names for the city. This decision aligns Wikipedia's content with that of many other contemporary English-language encyclopedia entries: the Encyclopaedia Britannica, for example, begins its article on this subject with "Istanbul, Turkish İstanbul, formerly Constantinople, ancient Byzantium, largest city and seaport of Turkey” (Britannica Online, 2018).

Unlike Britannica, however, whose production relies on small-scale, closed collaborations between individual authors, editors and publishers, the radical potential of wikis as websites that 'anyone can edit' encourages all readers who do not agree with the prevailing translation solution to propose their own alternative renderings. Moreover, the new software's technological logic of 'publish-then-filter' means they do not have to negotiate complex structures of editorial control in order to make public their revision but can engage directly with the text itself (Shirky, 2008: 98). For this reason, the platform regularly functions as a space for online disruption fuelled by offline conflicts and antagonisms, such as - in the case of Istanbul - those that have long existed between Greek and Turkish nationalist ideologies. Consequently, it is perhaps unsurprising to find that, beginning in 2006, contributors such as Khoikhoi, NikoSilver, Têlex and Hectorian make a series of interventions in opposition against the first solution described above (Figure 2). Although they agree that the name should be translated in this English-language article, they argue that it is necessary to also include the Greek name for the city as a source text for this translation. They each propose solutions such as that provided in Figure 3:

\section{Istanbul}

From Wikipedia, the free encyclopedia

Istanbul (Turkish: İstanbul, Greek: Kwvoтavтıvoúтroגn Konstandinúpoli; see other names)

Figure 3: The translation solution proposed by Khoikhoi, NikoSilver, Tēlex and Hectorian

Central to Khoikhoi's argument, on the one hand, is the fact that Istanbul was once home to a predominantly Greek-speaking population. In a Talk page comment posted at 17:39 on 9 October 2006 (Archive 2), for instance, he explains his preference for this translation solution, writing that "[t]he Greek name is there because for large parts of İstanbul's history, it was an important name used officially (under the Byzantine Empire) or by the local Greek population (under the Ottoman Empire). [...] I think it is a good thing to represent all the history of a place, not just its recent history." He also compares Istanbul with places such as Sibiu in Romania (German: Hermannstadt, Hungarian: Nagyszeben) and Lviv in Ukraine (German: Lemberg; Polish: Lwów; Russian: Львов, Lvov), noting that in these cases, the Wikipedia community has in fact promoted these other names as alternative source texts for the English-language translation. 
Tēlex adopts a similar but slightly different stance in his support for this new rendering. Like Khoikhoi, he too highlights the fact that the city has "been known by its Greek name since before the first Turk set foot on Anatolia" (Tēlex, 15:05, 23 June

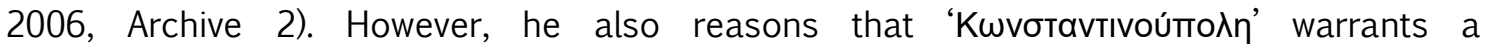
prominent position in the article because the city remains an important centre in modern Greek culture today. Although he admits the local Greek population now represents only a small minority, he makes the point that "the Patriarch of the Greek Orthodox Church is based in Istanbul" (Tēlex, 15:05, 23 June 2006, Archive 2). In this way, he foregrounds the fact that Istanbul has special religious and symbolic significance for modern Greek culture, operating as the equivalent of the Vatican in Rome for the Eastern Church. His fellow Greek compatriot NikoSilver (22:29, 19 October 2006, Archive 2; emphasis in original) agrees, insisting that the Greek name be made visible as a source text because "it is still known as such by many, and because Greece and many countries still officially call the city with this or similar names."

Wiki software precludes any translation solution from ever being fixed as final and therefore, despite the best efforts of Khoikhoi, Tēlex and NikoSilver, every attempt to impose their rendering on the article text is quickly 'reverted' (i.e. undone to the previous archived version) by other members of the community. The Talk page debate thus becomes increasingly heated as frustrations rise and more voices offer their opinions on the issue. It is in this stormy atmosphere that Hectorian puts forward what are perhaps the most contentious arguments made with respect to this translation

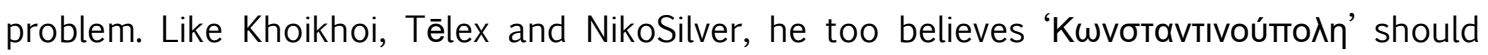
be signalled as a local name in the first line of the Wikipedia text; however, Hectorian goes significantly further in his attack on those who oppose such a strategy. He suggests that the reason there appears to be so much resistance to the inclusion of the Greek name as a source text is that the article has been co-opted by 'Turkish nationalists' seeking to remove all "info linked to Greeks/Greek language from the lead [i.e. the introduction]" (16:45, 19 October 2006, Archive 2). In this way, he contends, they would attempt to downplay the importance of Istanbul in Greek history and culture, and impose their own "nationalistic Turkish" point of view (POV) on the English-language text. In retaliation, he sees no option but to threaten his opponents with a linguistic form of guerrilla warfare:

\footnotetext{
if the greek name will not be added here as the turkish is in Alexandroupoli, Komotini, Xanthi, Thessaloniki, Symi, etc etc, i will begin by removing the turkish name from all those articles and many more... If this article has become "protected" by turkish nationalists and the admins are not interesting in intervening, that's the only semi-solution ... I've spoken and i will do it. Regards Hectorian (15:02, 20 October 2006, Archive 2)
}

In other words, Hectorian suggests that not just this Wikipedia article, but all Greekand Turkish-related entries, have been transformed into a new battleground between opposing ideologies by individuals armed and empowered by the interactive, open nature of the wiki environment. 
Interestingly, it is not only members of what we might call the 'anti-Turkish' faction of this Wikipedia community who launch such accusations. A couple of months later on 2 December 2006, an unregistered user adds the following message to the User Profile pages belonging to Hectorian, NikoSilver and a number of other Wikipedians involved in authoring the Istanbul page:

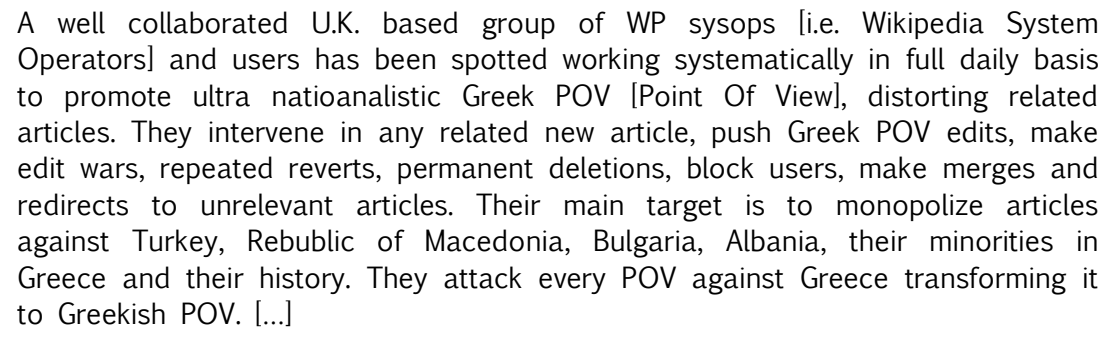

List of abusers involved:

user:Khoikhoi (sysop,) He has been probated and unprobated user:Future Perfect at Sunrise (sysop),

user:Aldux,

user:Tekleni,

user:Telex,

user:NikoSilver,

user:Euthymios,

user:Hectorian,

user:Politis,

user:Miskin

Some of them are suspected employees-agents of Greek National Intelligence Service (Е.Y.П.). Others are suspected members of ultra nationalistic organizations of Greek interests and some act as sockpuppets.

(Wikipedia, “User Talk: NikoSilver”, Revision as of 12:05, 2 December 2006)

This comment thus voices a perspective diametrically opposed to that raised in Hectorian's post quoted above. It suggests that many Greek- and Turkish-related entries have in fact been taken over by a cabal of "ultra natioanalistic" [sic] Greek volunteers, working on a "full daily basis". Through a coordinated series of edits, it continues, these contributors "distort" articles such as "Istanbul' and impose their "Greekish POV" on such texts. What is more, the comment also highlights the extent to which paranoia and suspicion are rife in the pseudonymous environment of the wiki platform. Most likely, Khoikhoi, Hectorian, NikoSilver and others have nothing to do with the Greek National Intelligence Service, but the faceless, virtual nature of their interactions mean users are left to judge each other's motives on the basis of their textual interventions in the encyclopedia's content. Consequently, allegations of this kind are by no means uncommon and may in fact never be fully disproven.

\section{Summary and conclusions}

Place names are of course never neutral. As Albin (2004), Baker (2006: 125) and others have discussed, these labels are often imbued with so much socio-cultural and political signification that their translation is almost invariably fraught with difficult 
decisions on the part of even the most ideologically disinterested translator. That said, the fact that the translation of 'Istanbul' seems to have provoked such a heightened level of argument here - and indeed, that similar 'edit wars' occur right across the Wikipedia platform (see Jones, 2017; 2018; 2019 [in press]) - should be interpreted as a product of the disruptive nature of wiki technologies. As this paper has attempted to show, little can be taken for granted within such fluid and open online environments; every word choice and every layout decision has the potential to develop into a source of conflict between the diverse members of this transnational community. My case-study has demonstrated how the ease with which wiki content can be changed and the absence of top-down editorial control dismantles the dichotomy of active translator and passive audience, empowering any reader to engage directly in the translation process and propose alternative renderings that conform to their world view. It has highlighted the always unfinished nature of these textual productions and thus the fact that no one solution can ever be fixed as final. Lastly, it has provided insight into the ways in which the pseudonymity of wiki participation additionally augments levels of interpersonal suspicion and paranoia, further stimulating the possibility of disagreement and discord within the community. These factors make for a highly disrupted translation process, rich in intrigue for scholars interested in the impact of new digital technologies on translators and their practices.

\section{Bibliography}

Albin, V. (2004). “Does Juliet's Rose, by Any Other Name, Smell as Sweet?", Translation Journal, 8(1) 〈http://www.translationjournal.net/journal/27names.htm〉. Page consulted on date: 31.01.18.

Baker, M. (2006). Translation and Conflict: A narrative account, London and New York: Routledge. DOI: 10.4324/9780203099919.

Benkler, Y. (2002). "Coase's Penguin, or, Linux and The Nature of the Firm", The Yale Law Journal, 112: 369-446. DOI: 10.2307/1562247.

Britannica Online. (2018). “Istanbul, Turkey” 〈https://www.britannica.com/place/Istanbul〉. Last updated: 21.02.18. Page consulted on date: 28.02.18.

Gardner, S. (2013). "Wikipedia, the People's Encyclopedia”, Los Angeles Times, January 13, 2013. 〈http://articles.latimes.com/2013/jan/13/opinion/la-oe-gardner-Wikipedia20130113>. Last updated: 13.01.13. Page consulted on date: 03.03.18.

Hartelius, E. J. (2010). "Wikipedia and the Emergence of Dialogic Expertise", Southern Communication Journal, 75(5): 505-526. DOI: 10.1080/10417940903377169

Hautasaari, A. and Ishida, T. (2011). "Discussion About Translation in Wikipedia", Proceedings of the Second International Conference on Culture and Computing, Washington, DC: IEEE, 127-128. DOI: 10.1109/Culture-Computing.2011.33 
Jones, H. (2019, in press). "Wikipedia as a Translation Zone: A heterotopic analysis of the online encyclopedia and its collaborative volunteer translator community", Target.

Jones, H. (2017). Multilingual Knowledge Production and Dissemination in Wikipedia: A spatial narrative analysis of the collaborative construction of city-related articles within the user-generated encyclopaedia, PhD diss., University of Manchester. <https://www.research.manchester.ac.uk/portal/en/theses/multilingual-knowledgeproduction-and-dissemination-in-wikipedia-a-spatial-narrative-analysis-of-thecollaborative-construction-of-cityrelated-articles-within-the-usergeneratedencyclopaedia(1bfe7cd6-7414-4a6c-9ebc-5c90a15fd9c6).html〉.

Jones, H. (2018). "Wikipedia, Translation, and the Collaborative Production of Spatial Knowledge", Alif: Journal of Comparative Poetics, 38: 264-297.

Jones, H. (forthcoming). "Wikis” in Baker, M., Blaagaard, B. and Pérez-González, L. (eds) (forthcoming) Routledge Encyclopedia of Citizen Media, London and New York: Routledge.

Leuf, B. and Cunningham, W. (2001). The Wiki Way: Quick collaboration on the Web, Boston: Addison-Wesley.

McDonough Dolmaya, J. (2012). "Analyzing the Crowdsourcing Model and its Impact on Public Perceptions of Translation”, The Translator 18(2): 167-191. DOI: 10.1080/13556509.2012.10799507

McDonough Dolmaya, J. (2015). "Revision History: Translation trends in Wikipedia", Translation Studies, 8(1): 16-34. DOI: 10.1080/14781700.2014.943279

McDonough Dolmaya, J. (2017). "Expanding the Sum of All Human Knowledge: Wikipedia, translation and linguistic justice", The Translator, 23(2): 143-157. DOI: 10.1080/13556509.2017.1321519

Reagle, J. M. Jr. (2010). Good Faith Collaboration: The Culture of Wikipedia, Cambridge, Massachusetts: MIT Press.

Shirky, C. (2008). Here Comes Everybody: How change happens when people come together, London: Penguin.

Shuttleworth, M. (2017). "Locating Foci of Translation on Wikipedia: Some methodological proposals", Translation Spaces, 6(2): 310-332.

Wikimedia, "Wikipedia editor activity statistics" 〈https://stats.wikimedia.org/EN/TablesWikipediaZZ.htm\#editor_activity_levels〉. Last updated: 12.03.18. Page consulted on date: 14.03.18.

Wikipedia, "Istanbul"〈https://en.wikipedia.org/wiki/Istanbul〉. Last updated: 06.03.18. Page consulted on date: 06.03.18.

Wikipedia, "Main page"〈https://en.wikipedia.org/wiki/Main_Page〉. Last updated: 31.01.18. Page consulted on date: 31.01.18. 
Wikipedia, "Talk: Istanbul”, Archive 1 〈https://en.wikipedia.org/wiki/Talk:Istanbul/Archive_1〉. Last updated: 01.09.07. Page consulted on date: 31.01.18.

Wikipedia, "Talk: Istanbul”, Archive 2 〈https://en.wikipedia.org/wiki/Talk:Istanbul/Archive_2〉. Last updated: 24.11.06. Page consulted on date: 31.01.18.

Wikipedia, "Talk: Istanbul”, Archive 3 〈https://en.wikipedia.org/wiki/Talk:Istanbul/Archive_3〉. Last updated: 21.01.08. Page consulted on date: 31.01.18.

Wikipedia, "Talk: Istanbul”, Archive 4 〈https://en.wikipedia.org/wiki/Talk:Istanbul/Archive_4〉. Last updated: 13.06.12. Page consulted on date: 31.01.18.

Wikipedia, "Talk: Istanbul”, Archive 5 〈https://en.wikipedia.org/wiki/Talk:Istanbul/Archive_5〉. Last updated: 23.04.12. Page consulted on date: 31.01.18.

Wikipedia, "Talk: Istanbul”, Archive 6 〈https://en.wikipedia.org/wiki/Talk:Istanbul/Archive_6〉. Last updated: 07.07.17. Page consulted on date: 31.01.18.

Wikipedia, "Talk: Istanbul”, Archive 7 〈https://en.wikipedia.org/wiki/Talk:Istanbul/Archive_7〉. Last updated: 31.05.13. Page consulted on date: 31.01.18.

Wikipedia, "User Talk: NikoSilver"〈https://en.wikipedia.org/wiki/User_talk:NikoSilver〉. Last updated: 23.11.15. Page consulted on date: 31.01.18.

Xtools, "Istanbul: Page History" 〈https://xtools.wmflabs.org/articleinfo/en.wikipedia.org/Istanbul〉. Last updated: 31.01.18. Page consulted on date: 31.01.18. 